\title{
Identifikasi Kekuatan Karakter pada Orang Tua yang Memiliki Anak Berkebutuhan Khusus
}

\author{
Uun Zulfiana \\ Fakultas Psikologi, Universitas Muhammadiyah Malang \\ e-mail: ${ }^{1}$ uun.zulfiana@umm.ac.id
}

\begin{abstract}
The presence of a child is a hope for parents. Hope parents have children who are born normal, physically and psychologically healthy. However, not all children are born perfectly according to the expectations of parents. The purpose of this study is to examine the level of character strength possessed by parents with children with special needs. The method used in this research is descriptive quantitative method. The value of the tool used is the scale value in action theory. of the 24 strengths or characters that are supported, based on the results of research on parents, as well as 5 aspects that have the highest total score compared to other characters. The 5 aspects are spirituality, gratitude, hope (hope), forgiveness (a sense of forgiveness), and curiosity (a sense of curiosity).
\end{abstract}

KEYWORDS Character strength, exceptional children, parents, spirituality

CITATION Zulfiana, Uun. (2019). Identifikasi kekuatan karakter pada orang tua yang memiliki anak berkebutuhan khusus. Cognicia, 7, (4). 411-418.

Kehadiran seorang anak merupakan harapan bagi orang tua. Harapan setiap orang tua adalah memiliki anak yang terlahir normal, sehat fisik maupun psikis. Akan tetapi, tidak semua anak lahir dengan sempurna sesuai harapan. Memiliki Anak Berkebutuhan Khusus (ABK) bukanlah hal mudah bagi orang tua. Berbagai respon yang dialami oleh orang tua dengan ABK di antaranya merasa malu, tidak percaya, terkejut, dan marah. Banyak dari mereka yang tidak memperhatikan dan mempedulikan pengasuhan ABK. Kurangnya penerimaan orang tua terhadap kondisi ABK biasanya disebabkan oleh penolakan memiliki anak berkebutuhan khusus. Selain itu, kurangnya sikap toleransi dan pengetahuan mengenai pola interaksi dan pola asuh ABK juga menjadi penyebabnya (Hing, Oliver, \& Everts, 2013).

Beberapa hal di atas menyebabkan orang tua akan merasa kesulitan dan tidak dapat menerima apa yang terjadi dalam keluarganya. Penerimaan ABK dalam keluarga memerlukan proses yang cukup panjang. Proses penerimaan orang tua pada ABK diawali dengan penolakan yang ditunjukkan dengan ketidakpercayaan, bingung, marah kepada diri sendiri, anak serta orang lain, yang kemudian dipenuhi rasa bersalah terhadap anak sehinga pada akhirnya orang tua dapat menerima kondisi anak (Purnomo, 2015). Namun, tidak semua orang tua bisa menerima kondisi mereka dengan memiliki ABK.

ABK bisa lahir di mana saja, dan dalam keluarga siapa saja, namun demikian tidak semua keluarga, khususnya orang tua dapat menerima dengan sepenuh hati 
kondisi anak spesial dengan kebutuhan khusus. Butuh waktu yang tidak sebentar untuk orang tua hingga dapat menerima kondisi anak mereka. Teori Batshaw, Perret dan Trachtenberg mengatakan bahwa orang tua yang melahirkan atau memiliki anak berkebutuhan khusus akan memiliki pola respon yang terbagi dalam lima fase, yaitu denial (penolakan), depression (depresi/bingung), anger \& guilty (marah \& rasa bersalah), bargaining (mempertimbangkan), dan acceptance (penerimaan).

Reaksi emosional tersebut bukanlah hal yang berlebihan dan wajar dirasakan oleh para orang tua yang memiliki anak berkebutuhan khusus. Hal ini merupakan reaksi awal dan akan menjadi masalah jika orang tua tidak bisa menangani permasalahan tersebut secara berkelanjutan. Permalasahan akan timbul dikarenakan orang tua tetap berjuang untuk mengasuh dan membesarkan anak dengan segala keterbatasan yang dimilikinya.

Jika permasalahan tersebut tidak segera diatasi, maka akan timbul permasalahan lain. Berdasarkan studi awal yang dilakukan oleh peneliti melalui metode wawancara di Pusat Layanan Pendidikan Anak Berkebutuhan Khusus Kota Malang pada tahun 2017, diperoleh hasil bahwa orang tua yang tidak menginginkan keberadaan $\mathrm{ABK}$ cenderung melakukan ignoring. Hal ini tercermin dari perilaku orang tua antara lain tidak mau mengantar anaknya ke pusat terapi, tidak menghadiri undangan penyuluhan dan konsultasi, bahkan bersikap tidak peduli dan menyerahkan pengasuhan anak mereka kepada kakek, nenek, atau pembantu.

Berbagai upaya pemerintah untuk menangani kasus ABK salah satunya dengan mendirikan Pusat Layanan ABK yang berada di Malang Bali. Pusat layanan untuk ABK pun tidak hanya menangani kasus pada anak saja, namun juga berupaya untuk memberikan penguatan untuk orang tua. Hal ini dimaksudkan agar orang tua dapat bekerjasama dengan pusat layanan sehingga kemampuan ABK dapat berkembang secara optimal.

Upaya yang dilakukan oleh pemerintah untuk memberikan penanganan pada orang tua $\mathrm{ABK}$ adalah pemberian konseling dan konsultasi oleh psikolog dua kali dalam setahun. Selain itu, pemberian penyuluhan baik dari tenaga medis maupun psikolog mengenai pola asuh dan cara bersikap terhadap ABK dilakukan setiap bulan. Agenda tersebut dilakukan untuk meningkatkan pemahaman dan penerimaan diri orang tua yang memiliki ABK.

Sejalan dengan apa yang telah diupayakan oleh pemerintah, pendekatan positif psikologi berusaha untuk memandang individu dari kacamata positif, dalam artian setiap individu memiliki kekuatan masing-masing (Peterson \& Seligman, 2004). Selama ini, pendekatan psikologi kontemporer cenderung memandang individu dari sisi kelemahannya, berdasarkan kriteria-kriteria yang tertulis di The Diagnostics and Statistical Manual of Mental Disorder dan Pedoman Penggolongan dan Diagnosis Gangguan Jiwa yang disusun berdasarkan International Statistical Clasification of Desease (ICD-10).

Konsep dalam menemukan kekuatan karakter individu berfokus pada emosi positif, sifat-sifat positif, dan tempat atau lingkungan yang positif. Emosi positif digambarkan dengan adanya harapan-harapan untuk masa depan dan kebahagiaan yang dirasakan oleh individu. Untuk mengembangkan emosi dan sifat positif, 
individu memerlukan lingkungan yang mendukung seperti pola asuh, toleransi, dan kebebasan untuk berpendapat (Seligman \& Csiskzentmihalyi, 2000).

Manuel D dan Rhoda Myerson Foundation (1998) selaku pusat riset berupaya untuk membuat alat ukur yang betujuan mengetahui kekuatan karakter individu sehingga dapat dioptimalkan. Dasar dibuatnya alat ukur ini adalah karena individu tidak lepas dari masalah dalam kehidupannya, terutama masalah psikologis. Oleh karenanya, dibutuhkan kemampuan dalam menyelesaikan permasalahan yang dihadapinya dengan tepat dan menitikberatkan pada potensi yang dimilikinya, yaitu kekuatan karakter. Alat ukur ini dinamakan Values in Action Inventory of Strength (VIAIS).

Berbagai masalah yang timbul pada orang tua ABK merupakan suatu krisis yang jika tidak mendapatkan penanganan yang baik akan berkesinambungan mengakibatkan masalah dalam kepemimpinan, integritas, dan subjective well being, sehingga pembentukan karakter menjadi tidak maksimal (Peterson, Park, Hall \& Seligman, 2009). Maka dari itu, pengoptimalan dan pengembangan karakter dengan baik dan maksimal sangat penting untuk dilakukan.

Berdasarkan 24 kekuatan karakter yang dimiliki oleh individu dari pandangan Psikologi Positif, terdapat lima besar kekuatan karakter yang dimiliki oleh individu yaitu gratitude, cinta, harapan, rasa ingin tahu, dan semangat. Penelitian tersebut dilakukan pada subjek remaja dan dewasa (Peterson, Ruch, Beermann, Park \& Seligman, 2007; Park, 2004).

Hasil yang sama juga didapatkan dari penelitian Soetjiningsih (2015), di mana gratitude, love, dan hope pada subjek dewasa berada pada kategori tertinggi dalam kekuatan karakter individu. Dari hasil tersebut terprediksi bahwa 3 kekuatan karakter tersebut mempengaruhi kesejahteraan individu. Hal ini senada dengan penelitian sebelumnya, yang menyatakan gratitude merupakan predictor terbesar dalam meningkatkan kebahagiaan lansia di panti wreda selain dukungan sosial (Zulfiana, 2014). Oleh karenanya, tujuan dari penelitian ini adalah untuk mengkaji tingkat kekuatan karakter yang dimiliki oleh orang tua dengan ABK. Hal ini dirasa penting karena dengan diketahui tingkat kekuatan karakter orang tua dengan $A B K$, dapat digunakan sebagai dasar untuk upaya peningkatan dan pengembangan karakter mereka sehingga tercapai kebahagiaan dan kesejahteraan psikologis.

\section{METODE PENELITIAN}

Penelitian ini merupakan penelitian kuantitatif deskriptif. Penelitian deskriptif yaitu penelitian yang berusaha untuk menjelaskan atau menerangkan suatu peristiwa berdasarkan data. Penelitian ini dilakukan dengan tujuan untuk melakukan uji validitas dan reliabilitas skala kebersyukuran kepada Tuhan. Penelitian dilakukan dalam 3 tahap, yaitu:

1. Tahap Pra Pelaksanaan

a. Menyiapkan skala penelitian yang akan diuji yaitu Value in Action Inventory of Strength.

b. Menentukan sekolah dan pusat terapi yang akan dijadikan tempat penelitian dan subjek penelitian. 


\section{Tahap Pelaksanaan}

a. Menjelaskan tujuan penelitian kepada subjek penelitian.

b. Membagikan skala kebersyukuran kepada Tuhan pada subjek penelitian.

3. Tahap Analisis Data

Pengolahan data yang akan dianalisis adalah data dari skala yang telah diisi oleh subjek penelitian hingga kemudian penyimpulan hasil penelitian.

Populasi merupakan seluruh individu yang dimaksudkan untuk diteliti dan nantinya akan digeneralisasikan. Generalisasi adalah suatu cara pengambilan kesimpulan terhadap individu yang lebih luas dan lebih besar jumlahnya berdasarkan data yang diperoleh dari sekelompok kecil individu yang diambil dari populasi (Hadi, 2001). Populasi pada penelitian ini adalah orang tua yang memiliki anak berkebutuhan khusus di Malang dan Pasuruan.

Sampel adalah sebagian kecil individu yang diajadikan wakil dalam penelitian. Pada penelitian ini sampel yang digunakan adalah sebagian populasi. Teknik pengambilan sampel dalam penelitian ini adalah random sampling. Suatu sampel dapat dikatakan diambil secara random apabila subjek dalam populasi memiliki peluang yang sama besar untuk terpilih menjadi sampel (Azwar, 2001).

Sampel pada penelitian ini berjumlah 100 orang tua yang memiliki ABK. Pengambilan sampel dengan jumlah tersebut dilakukan mengingat jumlah anak berkebutuhan khusus tidak sebanyak anak normal.

Metode pengumpulan data pada penelitian ini adalah Value in Action Inventory of Strength dengan mengambil kelima aspek Karakter Strenght yang terdiri dari; Zest (6 pernyataan), Love (6 pernyataan), Gratitude (6 pernyataan), Curiousity (6 pernyataan), dan Hope (6 pernyataan). Total pernyataan yang digunakan pada skala ini adalah 30 pernyataan.

Skala kebersyukuran disusun dalam bentuk skala ordinal dengan lima alternatif jawaban, yaitu Sangat Setuju (SS), Setuju (S), Cukup Setuju (CS), Tidak Setuju (TS) dan Sangat Tidak Setuju (STS). Cara penilaian terhadap pertanyaan atau pernyataan favourable pada jawaban SS, S, CS, TS dan STS adalah 5, 4, 3, 2, 1. Sebaliknya, untuk pertanyaan atau pernyataan unfavourable, jawaban SS, S, CS, TS dan STS masing-masing diberi skor 1, 2, 3, 4, dan 5 (Azwar, 2012).

Data yang diperoleh kemudian dianalisis dengan menggunakan statistik deskriptif yang berupa kategori dan persentase mengenai lima aspek kekuatan karakter yaitu love, gratitude, curiousity, hope dan zest. Selain itu, hasil analisis berupa ranking dari tertinggi sampai terrendah didasarkan pada lima karakter tersebut.

\section{HASIL PENELITIAN}

Tabel di bawah ini akan mendeskripsikan hasil penelitian berupa data demografi orang tua anak berkebutuhan khusus, antara lain;

\begin{tabular}{ccc}
\hline Aspek Kekuatan Karakter & Total Skor & Persentase (\%) \\
\hline Spirituality & 4554 & $6.34 \%$ \\
\hline Gratitude & 4358 & $6.06 \%$ \\
\hline Hopefulness & 4312 & $6.00 \%$ \\
\hline Forgiveness & 4148 & $5.77 \%$ \\
\hline
\end{tabular}




\begin{tabular}{ccc}
\hline Curiosity & 3860 & $5.37 \%$ \\
\hline Love & 3822 & $5.32 \%$ \\
\hline Kindness & 3750 & $5.22 \%$ \\
\hline Integrity & 3048 & $4.24 \%$ \\
\hline Citizenship & 2847 & $2.96 \%$ \\
\hline Perspective & 2818 & $3.92 \%$ \\
\hline Leadership & 2721 & $3.79 \%$ \\
\hline Humility & 2591 & $3.61 \%$ \\
\hline Social Intelligence & 2577 & $3.59 \%$ \\
\hline Self Regulation & 2571 & $3.58 \%$ \\
\hline Vitality & 2514 & $3.50 \%$ \\
\hline Humour & 2500 & $3.48 \%$ \\
\hline Creativity & 2449 & $3.41 \%$ \\
\hline Perserverance & 2432 & $3.38 \%$ \\
\hline Open Mindedness & 2425 & $3.37 \%$ \\
\hline Bravery & 2380 & $3.31 \%$ \\
\hline Appreciation Of Beauty & 2336 & $3.25 \%$ \\
\hline Fairness & 2319 & $3.23 \%$ \\
\hline Love OfLearning & 2307 & $3.21 \%$ \\
\hline Prudence & 2224 & $3.09 \%$
\end{tabular}

Berdasarkan tabel di atas, terkait hasil analisis yang diambil dari data yang telah diberikan kepada 100 orang tua yang dituju pada enam sekolah luar biasa (SLB), diketahui bahwa dari ke-24 character strength atau kekuatan karakter yang diteliti, terdapat 5 aspek yang memiliki total nilai tertinggi dibandingkan dengan karakter lainnya. 5 aspek tersebut di antaranya adalah spirituality (kerohanian), gratitude (rasa bersyukur), hopefulness (harapan), forgiveness (rasa untuk memaafkan), dan curiosity (rasa keingintahuan). Dari hasil penghitungan persentase kekuatan karakter per tiap aspek, seperti yang terdapat dala tabel di atas, diketahui bahwa spirituality yang memiliki persentase paling besar yakni 6,34\%. Sedangkan untuk aspek lainnya terdapat gratitude sebesar 6,06\%, hopefulness sebanyak 6\%, forgiveness yakni 5,77\%, dan curiosity sebesar 5,37\%.

Mengacu pada penelitian terdahulu oleh Peterson, Ruch, Beermann, Park, \& Seligman, (dalam Park, 2004) yang berfokus dengan subjek remaja dan dewasa, kekuatan karakter yang dimiliki oleh individu terkait justru pada gratitude, cinta, harapan, rasa ingin tahu, dan semangat. Namun, bila lebih difokuskan pada spesifikasi subjek dalam penelitian ini, yang mengarah pada orang dewasa dan memiliki anak berkebutuhan khusus, menunjukkan adanya korelasi antara masing-masing kekuatan karakter yang mengarah kepada kebahagiaan dan pencapaian kesejahteraan secara psikologis. Aspek tertinggi dari hasil penelitian tersebut berkolerasi positif dan kekuatan sangat kuat terkait dengan terwujudnya kesejahteraan psikologis yang muncul untuk berkaitan dengan berbagai orientasi kebahagiaan. 


\section{DISKUSI}

Berdasarkan hasil analisis data penelitian, hal yang didapatkan adalah bahwa Peterson \& Seligman membedakannya dalam tiga level konseptual yang tentunya dimiliki oleh tiap individu, yaitu kebajikan (virtue) terkait dengan bagaimana suatu individu memiliki karakter yang baik. Kemudian kekuatan karakter (character strength) yang merupakan trait positif pada suatu individu. Terakhir adalah situational themes, yakni situasi yang mendorong seseorang untuk melihat kekuatan karakter dengan cara tertentu hingga dapat ditampilkan secara berbeda di setiap individu, sehingga penelitian ini berfokus pada bagaimana orang tua yang memiliki anak berkebutuhan khusus sebagai subjek penelitian terkait dengan kekuatan karakter yang ada dalam dirinya. Dilihat pula dari situasi yang mendorong orang tua hingga memiliki kekuatan karakter tersebut, di mana mereka tidak pernah memiliki dugaan maupun harapan untuk mempunyai anak yang berkebutuhan khusus. Selain itu, dengan kondisi di mana belum tentu memiliki kesiapan untuk menerima situasi seperti itu. Pada penelitian ini, lima aspek kekuatan karakter yang tertinggi di antaranya adalah spirituality (kerohanian), gratitude (rasa bersyukur), hopefulness (harapan), forgiveness (rasa untuk memaafkan), dan curiosity (rasa keingintahuan).

Sedangkan pada penelitian dari Peterson, Ruch, Beermann, Park \& Seligman, (dalam Park, 2004) dengan subjek remaja dan dewasa, hanya terdapat tiga aspek kekuatan karakter yang sama, yaitu gratitude (rasa bersyukur), hopefulness (harapan), dan curiosity (rasa keingintahuan) dari kelima aspek yang tertinggi dari hasil penelitiannya. Selain itu, dalam penelitian Soetjiningsih (2015) yang didapati hasil adanya tiga aspek kekuatan karakter individu yang paling ditekan dalam penelitiannya dengan subjek adalah orang dewasa, hanya terdapat dua aspek kekuatan karakter yang serupa yaitu gratitude dan hope.

Terdapat tiga aspek yang memiliki skor tertinggi pada penelitian ini mengarah pada kekuatan karakter transcedence atau transedensi. Transedensi sendiri merupakan kemampuan dalam menjalin hubungan dengan kekuatan semesta yang lebih besar dan ketika suatu individu memaknai kehidupannya. Ketiga aspek tersebut di antaranya adalah spiritualitas dan religiusitas yang mengarah pada keyakinan dengan mendorong dan menentukan makna hidup. Selain itu juga dari spiritualitas mengarah pada bagaimana cara manusia untuk menjalin hubungan sosial di lingkungannya.

Dilansir dari penjelasan VIA Institute, spirituality atau kerohanian sendiri adalah keyakinan yang dipegang oleh seseorang hingga menjadi suatu bagian yang berarti, sehingga membentuk perilaku, memberikan rasa nyaman, pengertian, dan tujuan pada diri seseorang tersebut. Spiritualitas sendiri dipandang menjadi penyeimbang dalam hidup terutama di kehidupan yang menuntut seorang individu tersebut untuk bergerak lebih cepat dan berusaha untuk mencari makna kehidupan. Spiritualitas menjadi penyeimbang serta coping strategy bagi sebagian orang agar memiliki kebahagaiaan dan ketenangan hidup, walaupun memiliki permasalahan yang tidak dimiliki sembarang orang seperti memiliki anak yang berkebutuhan khusus. Terdapat suatu penelitian yang menyebutkan bahwa religiusitas dan spiritualitas menjadi hal yang dapat membantu seorang individu saat mengalami suatu peristiwa atau kondisi menekan yang dapat menimbulkan stres dan kesulitan saat menghadapi 
situasi tersebut (Cook and Wimberley 1983; Bufford 1991; Ellison et al. 2001; Strawbridge et al.1998; Krause, 2006 dalam Ellison dan Fan, 2008).

Aspek transedensi selanjutnya adalah gratitude yang menjadi aspek yang dimiliki dari penelitian-penelitian sebelumnya terkait kekuatan karakter. Gratitude sendiri merupakan suatu penghargaan yang berupa rasa terima kasih serta apresiasi terhadap hal yang suatu individu tersebut telah dimiliki dalam kehidupannya ataupun terkait segala hal yang terjadi dalam hidupnya. Gratitude melibatkan pengetahuan ketika menerima sesuatu dan bersyukur atas apa yang diterimanya. Melihat dari hasil penelitian yang dilakukan, orang tua yang memiliki anak berkebutuhan khusus telah menerima hal-hal yang terjadi dalam kehidupannya, walaupun hal tersebut terkadang dirasa berat, namun mereka dapat tetap bersyukur dengan situasi dan kondisi yang terjadi dalam kehidupannya. Kebersyukuran dan penerimaan terkait apa yang didapat dalam kehidupan dapat menjadi suatu kekuatan tersendiri untuk mengantarkan anakanak berkebutuhan khusus dalam tumbuh dan berkembang.

Selanjutnya adalah aspek hopefulness atau harapan, yang merupakan salah satu aspek kekuatan karakter transedensi terkait berpikir mengenai masa depan dan berharap pada sesuatu yang diinginkan. Tidak ada satu pun orang tua yang tidak memiliki harapan pada anaknya sesuai dengan apa yang diinginkan dalam pikirannya. Terutama pada orang tua yang memiliki anak berkebutuhan khusus, mereka akan berpikir dengan keterbatasan yang anaknya miliki, anak yang berkebutuhan khusus tersebut dapat memiliki kebahagiaan dan mencapai kemandirian dalam kehidupannya. Maka dari itu, orang tua yang memiliki kekuatan karakter hopefulness cenderung memberikan pendidikan dengan memasukkan anak-anak mereka di Sekolah Luar Biasa (SLB).

Dua kekuatan karakter lainnya yang memiliki skor tinggi di antaranya adalah forgiveness (memaafkan) dan curiosity (rasa ingin tahu). Bila melihat dari penjelasan VIA Institute terkait aspek character strength tersebut, aspek forgiveness atau rasa untuk memaafkan merupakan karakter di mana seseorang dapat melepaskan rasa sakit yang dialami karena telah dirugikan hingga mampu memberikan kesempatan kedua pada pihak yang telah merugikan, yang membuat tidak memiliki rasa dendam ataupun rasa kesal. Hal tersebut mengarah pada rasa memaafkan bagi diri yang mungkin membuat kesalahan hingga memiliki anak berkebutuhan khusus, atau hal lain yang membuat mereka berpikir untuk patut disalahkan. Dengan cara memaafkan, orang tua dapat berpikir logis terkait masa depan yang akan dihadapi oleh dirinya dan anaknya. Aspek curiosity atau rasa keingintahuan adalah karakter yang membuat seseorang memiliki ketertarikan pada suatu hal yang baru, seperti pada kegiatan, gagasan, dan orangorang baru, sehingga membuatnya menjadi pribadi yang terbuka untuk pengalaman baru. Curiosity dapat mengarah pada rasa keingintahuan orang tua untuk memberikan treatment atau penanganan bagi anak-anaknya agar dapat lebih baik daripada sebelumnya, maupun mencari ilmu terkait dengan kondisi anak-anaknya.

\section{SIMPULAN DAN IMPLIKASI}

Kesimpulan dari penelitian mengenai identifikasi kekuatan karakter pada orang tua $\mathrm{ABK}$ dari pandangan psikologi positif adalah spiritualitas, gratitude 
(kebersyukuran), hopefulness (harapan), forgiveness (memaafkan) dan curiosity (rasa ingin tahu).

Implikasi yang berdasarkan dari hasil penelitian ini adalah dengan diketahuinya kekuatan karakter pada orang Tua ABK, maka dapat mempermudah peneliti selanjutnya untuk mengembangankan penelitian dan modul intervensi sesuai dengan kekuatan karakter masing-masing dari mereka. Dengan begitu, orang tua ABK terbantu untuk memahami dirinya dan mengembangkan karakter yang dimiliki sehingga dapat tercapai penerimaan diri, subjective well being, dan happiness.

\section{DAFTAR PUSTAKA}

Diener, E., Lucas, R. E., \& Oishi, S. (2005). Subjective well-being: The science of happiness and life satisfaction. In C. R. Snyder \& S. J. Lopez (Eds.), Handbook of positive psychology (2nd ed.), New York, NY: Oxford University Press.

Duckworth, A. L., Steen, T. A., \& Seligman, M. E. P. (2005). Positive psychology in clinical

Kashdan, T.B., Uswatte,G. \& Julian, T. (2006). Gratitude and hedonic and eudaimonic wellbeing in Vietnam War veterans. Behaviour Research and Therapy. 44, 177-199.

Larsen, J.T \& McKibban. A. R. (2008). Is happiness having what you want, wanting what you have, or both?. Psychological Science. 19 (4), 371-377.

Manuel D dan Rhoda Myerson Fondation (1999). Dallas. Umited States of America.

McCullough, M. E., Tsang, J. \& Emmons, R.A. (2004). gratitude in intermediate affective terrain: Links of grateful moods to individual differences and daily emotional experience. Journal of Personality and Social Psychology. 86, (2), 295-309.

Meyer, P. S., Johnson, D. P., Parks, A., Iwanski, C. \& Penn, D. L. (2012). Positive living: A pilot study of group positive psychotherapy for people with schizophrenia. The Journal of Positive Psychology. 1, 1-10.

Mutrofin, S.H. (2006). Pengantar metode riset evaluasi. LaksBang PressIndo. Yogyakarta.

Park, C. L. \& Blumberg, C. J. (2002) Disclosing trauma through writing: testing the meaningmaking hypothesis. Cognitive Therapy and Research. 26, 597- 616.

Park. N., Peterson, C. \& Seligman, M. (2006). Streng of character and well-being. Journal of Social and Clinical Psychology. 23 (5),603-619.

Peterson, C. Ruch, W., Beermann, U. Park, N \& Seligman, M. E. P. (2007). Strength of character, orientation to happiness and life satisfaction. The journal of positive psychology. 2 (3), 149-156.

Rashid, T. (2008) Positive psychotherapy. In Lopez SJ (ed.) Positive Psychology: Exploring the best in people. Vol.4. Westport, C.T. Praeger Publishers.

Seligman, M. E. P. (2002). Authentic happiness: Using the new positive psychology to realize your potential for lasting fulfillment. New York.

Seligman, M. E. P., Steen, T. A., Park, N., \& Peterson, C. (2005). Positive psychology progress: Empirical validation of interventions. American Psychologist. 60, 410 - 421.

Seligman, M. E. P., Rashid, T., \& Parks, A. C. (2006). Positive psychotherapy. American Psychologist. 61, $774-788$.

Snyder, S. R \& Lopez, S. J. (2005). Handbook of Positive Psychology. Oxford University Press.

Wood, A. M., Froh, J.J \& Geraghty, A.W.A. (2010). Gratitude and well-being: A review and theoretical integration. Clinical Psychology Review. 30, 890-905

Zulfiana, U (2012), Psikoterapi Positif untuk Meningkatkan Kebahagiaan Lansia di Panti Wreda. Jurnal Sains dan Praktik Psikologi. Vol 2 (3). 256-267. 